\title{
FOXP3 and CTLA4 overexpression in multiple myeloma bone marrow as a sign of accumulation of $\mathrm{CD4}^{+} \mathrm{T}$ regulatory cells
}

\author{
Walter Moises Tobias Braga • Bruna Raphaeli da Silva • Ana Carolina de Carvalho • \\ Yumi H. Maekawa • Adriana Bruscato Bortoluzzo $\cdot$ Edgar Gil Rizzatti • \\ Djordje Atanackovic · Gisele Wally Braga Colleoni
}

Received: 2 February 2014 / Accepted: 12 July 2014 / Published online: 7 August 2014

(C) The Author(s) 2014. This article is published with open access at Springerlink.com

\begin{abstract}
Introduction Multiple myeloma (MM) development involves a series of genetic abnormalities and changes in the bone marrow $(\mathrm{BM})$ microenvironment, favoring the growth of the tumor and failure of local immune control. $\mathrm{T}$ regulatory (Treg) cells play an important role in dampening anti-tumor immune responses while T-helper-17 (Th17) cells seem to be critical for the eradication of malignant cells. The aim of our study was to characterize the expression of Treg- and Th17-related genes in total myeloma $\mathrm{BM}$ samples to assess their role as biomarkers, prognostic factors, and possible therapeutic targets in this incurable disease.

Methods Expression of markers for Treg (FOXP3, CTLA4) and Th17 cells $(R O R \gamma t)$ was determined by quantitative
\end{abstract}

Electronic supplementary material The online version of this article (doi:10.1007/s00262-014-1589-9) contains supplementary material, which is available to authorized users.

W. M. T. Braga $(\bowtie) \cdot$ B. R. da Silva · A. C. de Carvalho • G. W. B. Colleoni $(\square)$

Universidade Federal de São Paulo [UNIFESP], Rua Diogo de

Faria, 824, $5^{\circ}$ andar, Hemocentro, São Paulo CEP 04037-003, Brazil

e-mail:wmoises@uol.com.br

G. W. B. Colleoni

e-mail: gcolleoni@unifesp.br

Y. H. Maekawa · E. G. Rizzatti

Fleury Medicina e Saúde, São Paulo, Brazil

A. B. Bortoluzzo

Insper Institute of Education and Research, São Paulo, Brazil

D. Atanackovic

University Medical Center Hamburg-Eppendorf, Hamburg,

Germany real-time PCR in BM aspirates of $46 \mathrm{MM}$ patients, four patients with monoclonal gammopathy of undetermined significance, five solitary plasmacytomas, and five healthy BM donors. Gene expression was evaluated regarding an influence on the patients' overall survival (OS).

Results FOXP3 and CTLA4 presented a sixfold $(p=0.02)$ and 30-fold higher expression $(p=0.03)$, respectively, in MM patients than in controls. ROR $\gamma t$ expression was similar in MM patients and controls. Median OS of MM patients was 16.8 (range 4.5-29.1) months, and international staging system was the only independent prognostic factor for patients survival.

Conclusions Overexpression of FOXP 3 and CTLA4 in total BM samples suggests a local accumulation of immunosuppressive Tregs, the MM tumor environment, possibly dampening anti-tumor host immune responses. Therapeutic approaches targeting Treg cells and restoring local antitumor immunity may provide new treatment strategies for this incurable malignancy.

Keywords Multiple myeloma $\cdot$ FOXP3 $\cdot$ CTLA4 $\cdot$ Treg · Therapy

$\begin{array}{ll}\text { Abbreviations } \\ \text { BM } & \text { Bone marrow } \\ \text { CTLA4 } & \text { Cytotoxic T lymphocyte-associated antigen 4 } \\ \text { FOXP3 } & \text { Member of the forkhead/winged helix family } \\ \text { IL } & \text { Interleukin } \\ \text { iTreg } & \text { Induced Treg } \\ \text { ISS } & \text { International staging system } \\ \text { MGUS } & \begin{array}{l}\text { Monoclonal gammopathy of undetermined } \\ \text { significance }\end{array} \\ \text { MM } & \text { Multiple myeloma } \\ \text { nTreg } & \text { Natural Treg } \\ \text { OS } & \text { Overall survival }\end{array}$




$\begin{array}{ll}\text { qPCR } & \text { Quantitative real-time PCR } \\ \text { RUNX1 } & \text { Runt-related transcription factor 1 } \\ \text { ROR } \gamma \text { t } & \text { Orphan nuclear receptor } \gamma \text { t } \\ \text { SP } & \text { Solitary plasmacytoma } \\ \text { STAT 3 } & \text { Signal transducer and activator of transcription 3 } \\ \text { TCR } & \text { T cell receptor } \\ \text { Teff } & \text { T effector cells } \\ \text { TGF } \beta & \text { Transforming growth factor } \beta \\ \text { Th1 } & \text { T-helper 1 } \\ \text { Th2 } & \text { T-helper 2 } \\ \text { Treg } & \text { T regulatory } \\ \text { Th17 } & \text { T-helper-17 }\end{array}$

\section{Introduction}

Multiple myeloma (MM) development involves a series of genetic abnormalities and changes in the bone marrow (BM) microenvironment, favoring the growth of the tumor and the failure of local immune control. Cellular immune defects in MM include decreased number of $\mathrm{CD} 19^{+} \mathrm{B}$ cells as well as $\mathrm{CD}^{+}$and $\mathrm{CD} 8^{+} \mathrm{T}$ cells. The presence of these abnormalities seems to negatively correlate with survival, indicating a potential relationship between cellular immune components and disease control [1]. A significant impairment of $\mathrm{T}$ cell function has been described for MM patients and for patients with monoclonal gammopathy of undetermined significance (MGUS) [2].

Subpopulations of $\mathrm{CD}^{+} \mathrm{T}$ cells, such as $\mathrm{T}$ regulatory (Treg) and T-helper-17 (Th17) cells, have emerged as a key players in the immune control of cancer. Representing $5-10 \%$ of all $\mathrm{CD}^{+} \mathrm{T}$ cells in the peripheral blood, Tregs express CD4 and CD25 surface antigens as well as cytoplasmic (cytotoxic T lymphocyte-associated antigen 4) CTLA4 and GITR. Treg cells control many facets of immune responses in an attempt to maintain immune homeostasis, ranging from autoimmune diseases to inflammatory conditions and cancer. Two major Treg populations have been reported to date. Natural Treg (nTreg) cells develop in the thymus and constitute a critical arm of active mechanisms of peripheral tolerance, particularly to selfantigens. A growing body of knowledge supports the existence of induced Treg (iTreg) cells, which may derive from conventional CD4 $+\mathrm{T}$ cells. CD4 $+\mathrm{T}$ cells are induced by IL-10 and secrete both IL-10 and transforming growth factor $\beta$ (TGF $\beta$ ) converting peripheral naïve $\mathrm{CD} 4+\mathrm{CD} 25-$ FOXP3- cells to FOXP3-expressing cells. Regardless of their origin, they share one key feature: their ability to potently suppress effector $\mathrm{T}$ cells (Teff). This suppressive activity of Treg cells is associated with the overexpression of FOXP3, a member of the forkhead/winged helix family, which acts as a transcriptional repressor [3], and CTLA4, a coinhibitory molecule that maintains immune homeostasis by down regulating $\mathrm{T}$ cell-related costimulatory pathways. FOXP3-expressing cells in cancer settings have been correlated with poor anti-tumor effector response, hence compromising tumor immunity $[4,5]$.

Currently, many studies are focusing on Treg populations in MM, and a lot of controversy has been found in this field. While Prabhala et al. [2] showed an increase in $\mathrm{CD} 4+\mathrm{CD} 25+$ in peripheral blood and BM of monoclonal gammopathy of undetermined significance (MGUS) and MM patients when compared with controls, they also found that Treg cells-evaluated by FOXP3 expression-are significantly decreased in number and function in patients with MGUS and MM compared with healthy donors. In other study, Gupta et al. [6] reported a decrease in frequency of Treg as well as reduced expression of FOXP3 by flow cytometry in peripheral blood samples of untreated MM patients, which increased significantly after treatment with thalidomide. Furthermore, Treg MM cells exhibited immunosuppressive activity in vitro [6]. On the other hand, Beyer et al. [7] demonstrated in both MGUS and MM that functional FOXP3+ Treg cells of naive, central, and effector memory phenotype (evaluated by CCR7 and CD45RA expression) are significantly expanded. The last study was supported by Feyler et al. [8] that showed significantly elevated levels of functional CD4+ CD25+ FOXP3 + Treg cells obtained from peripheral blood samples and analyzed by flow cytometry in MGUS and MM in comparison with healthy controls.

Th17 cells, a recently described IL-17-expressing CD4 ${ }^{+}$ $\mathrm{T}$ cell subset, protect hosts against fungal and parasitic infections and participate in inflammatory reactions and autoimmunity. One of the main Th17-specific transcription factors is the orphan nuclear receptor, ROR $\gamma$. Its specific isoform ROR $\gamma \mathrm{t}$ is selectively expressed by Th17 cells and regulated by STAT3. Overexpression of ROR $\gamma t$ promotes Th17 differentiation while inhibiting Th1 and Th2 development $[9,10]$. The role of Th17 cells in tumor pathogenesis is still not well defined. However, it seems that the balance between Treg and Th17 cells is particularly important for maintaining the homeostasis of anti-tumor immunity [11]. FOXP3 plays a negative role in IL-17 expression through physical interaction with RUNX1 and ROR $\gamma \mathrm{t}$, thereby inhibiting their transactivation activity. RUNX1 is highly expressed in $\mathrm{CD}^{+}{ }^{+} \mathrm{T}$ cells as well as $\mathrm{FOXP} 3^{+}$Tregs and interaction between RUNX1 and FOXP3 is essential for FOXP3 function. RUNX1 also has a significant role in Th17 differentiation due to its ability to induce ROR $\gamma \mathrm{t}$ expression and to associate with and to act together with ROR $\gamma t$ to induce $I L 17$ transcription [12].

Increased number of Th17 cells in MM BM in comparison with peripheral blood has also been described. Dhodapkar et al. [13] demonstrated that the proportion of Th17 cells in the BM of MM patients was higher than in 
peripheral blood samples. Moreover, functional properties varied according to compartment: MM BM samples contained a significantly higher proportion of polyfunctional Th17-1 cells than peripheral blood, and these cells were not observed in MGUS BM samples. IL-6, TGF $\beta$, and IL-1 play an important role in MM immune dysfunction. Since IL- 6 and TGF $\beta$ are also important for the generation of Th17 cells, Prabhala et al. [11] observed a significantly elevated baseline and induced frequency of Th17 cells in peripheral blood and BM from MM patients compared with controls. They confirmed a significant increase in IL-17, IL-21, IL-22, and IL-23 serum levels in blood and $\mathrm{BM}$ in $\mathrm{MM}$ compared with healthy controls and that IL-17 promotes MM cell growth and colony formation via IL-17 receptor, adhesion to BM stromal cells and increased growth in the in vivo murine xenotransplant model of human MM cell lines. The authors concluded that Th17 cells play an important role in MM pathobiology and may be an important therapeutic target for anti-tumor effect [11].

In this scenario, we believe that the balance between Treg and Th17 cells is important in the BM of MM. Also, exploring this concept may be more relevant than previous results that used exclusively peripheral blood samples or analyses only one of these $\mathrm{CD} 4^{+}$populations. Therefore, the aim of this study was to simultaneously characterize the expression of Treg (FOXP3 and CTLA4)- and Th17 $(R O R \gamma t)$-related genes in total MM BM samples in order to assess the local immune milieu as potential biomarker/ therapeutic target and to understand whether these genes have a prognostic impact on this incurable disease.

\section{Materials and methods}

\section{Patients}

Forty-six newly diagnosed MM patients referred to the Hematology and Hemotherapy Service of Federal University of São Paulo (UNIFESP) in São Paulo, Brazil were collected between 2003 and 2012. Only patients with no previous chemotherapy, corticosteroid, or bisphosphonate treatment were included. The diagnosis of MM was based on The International Working Group Criteria [14], and information on tumor stage was obtained for all patients according to Durie-Salmon and the international staging system (ISS) [15]. According to the ISS, 6 cases were classified as stage I, 13 as stage II, 23 as stage III, and 4 cases could not be classified because of the absence of beta2microglobulin data (Table 1). Patients were treated with dexamethasone/thalidomide or melphalan/prednisone/thalidomide, depending on their age and performance status, and 5 patients also received high-dose melphalan followed
Table 1 Multiple myeloma characteristics at diagnosis $(N=46)$

\begin{tabular}{ll}
\hline Characteristics & \\
\hline Median age, years (range) & $66(27-95)$ \\
Sex, $n(\%)$ & $25(54)$ \\
Male & $21(46)$ \\
Female & \\
Type of M-protein, $n(\%)$ & $09(20)$ \\
IgA & $25(54)$ \\
IgG & $01(02)$ \\
IgM & $04(09)$ \\
Light chain disease & $07(15)$ \\
NA & \\
D\&S stage, $n(\%)$ & $02(04)$ \\
I & $01(02)$ \\
II & $43(94)$ \\
III & \\
ISS & $06(13)$ \\
1 & $13(28)$ \\
2 & $23(50)$ \\
3 & $04(09)$ \\
NA &
\end{tabular}

$D \& S$ Durie-Salmon classification, ISS international staging system, $N A$ not available

by autologous stem cell transplantation. We also studied BM aspirates from 4 patients with MGUS, 5 patients with solitary plasmacytoma (SP), and 5 healthy BM donors (not age matched with patients' group). Written informed consent was obtained from all patients and controls, and the study was approved by the Ethical Committee of this institution.

Magnetic sorting of CD138-positive cells

BM samples were collected in sterile EDTA tubes during routine diagnostics, and neoplastic plasma cells were separated by magnetic sorting of CD138-positive cells using the MACS system (Magnetic Cell Sorting of Human Cells; Miltenyi Biotec, Bergisch-Gladbach, Germany), according to previous descriptions [16].

Flow cytometry

For the analysis of Treg cells in total BM, the flow through (after CD138 $8^{+}$sorting) cells of $13 \mathrm{MM}, 1 \mathrm{SP}, 2$ MGUS patients, and 3 healthy donors were stained with allophycocyanin (APC)-H7-Clone SK7-labeled anti-CD3, peridininchlorophyll-protein complex (PerCP)-Clone SK3-labeled anti-CD4 and fluorescein isothiocyanate (FITC)-M-Clone A251-labeled anti-CD25 antibodies (BD Biosciences, NSW, Australia). Intracellular labeling with PE-conjugated 
anti-FOXP3-Clone 236a/E7 and anti-CTLA4-APC-Clone BNI3 was followed by permeabilization with fix/perm solution according to the manufacturer's protocol (BD Biosciences). Flow cytometry was carried out using a BD FACScanto II (BD Biosciences), and lymphocytes were gated based on their forward and side light scatter properties. Data were analyzed with Infinicyt software (Cytognos SL, Salamanca, Spain). After gating the lymphocyte population, $\mathrm{CD} 3{ }^{+} \mathrm{CD} 4{ }^{+} \mathrm{CD} 25^{\text {high }} \mathrm{FOXP} 3{ }^{+} \mathrm{CTLA} 4^{+}$populations showing a Treg phenotype were sequentially gated and analyzed [17, 18]. Proportional numbers of Treg cells were calculated from target cell frequency as determined by flow cytometry and total lymphocyte counts calculated during routine diagnostics.

\section{RNA extraction}

RNA extraction from mononuclear cells (MNC) derived from total BM was performed as previously described [19]. Expression of genes related to the Treg and Th17 subpopulations, respectively, was evaluated by quantitative real-time PCR (qPCR) using 7500 Real Time PCR System (Applied Biosystems, Foster City, CA). Commercially available qPCR assays were used: FOXP3 (Hs01085834_m1*), CD25 (Hs00907779_m1*), TGF 1 (Hs00998133_m1*), CTLA4 (Hs03044418_m1*), RORyt (Hs01076112_m1*), IL6 (Hs00985639_m1*), and IL-17A (Hs00174383 m1*).

Expression of target genes was normalized by the arithmetic mean of triplicates of housekeeping genes ( $A C T \beta$ and $G A P D H)$ [19]. Samples containing no cDNA were used as negative controls. All samples were analyzed in triplicate. The relative mRNA expression level of the target genes was calculated using the $2^{-\Delta \Delta C T}$ method [20]. Genes were considered differentially expressed in tumor samples when their expression levels showed at least a twofold increment or decrease in comparison with normal samples.

Statistical analysis

Associations between the variables were tested by the Pearson's chi-squared test $\left(\chi^{2}\right)$. The Mann-Whitney test was used to compare two individual values. Pearson's product-moment correlation coefficient (Pearson's $r$ ) was used to measure the strength of linear dependence between two variables. Overall survival (OS) was calculated from the date of diagnosis of MM until death or last follow-up. Actuarial probabilities of OS were estimated according to the Kaplan-Meier method, and the curves were compared using the log-rank test. Cox's regression model was also employed to evaluate which variables could be considered independent prognostic factors. Differences with a $p<0.05$ were regarded as statistically significant. Statistical analyses were performed using SPSS Software version 14.0 (SPSS Inc., Chicago, IL) and Prism 5 software (GraphPad, San Diego, CA).

\section{Results}

The present study aimed at describing the bone marrow environment of MM with regard to the presence of Tregs and Th17 cells. Determining the frequency of these immunomodulating $\mathrm{T}$ cell subtypes in whole BM could theoretically be hampered by expression of the respective marker genes by tumor cells themselves. Therefore, in a first step, we checked whether FOXP3, CTLA4, and RORyt were aberrantly expressed by malignant plasma cells. The results showed a 125 -fold lower FOXP3 expression $(p=0.0001)$,
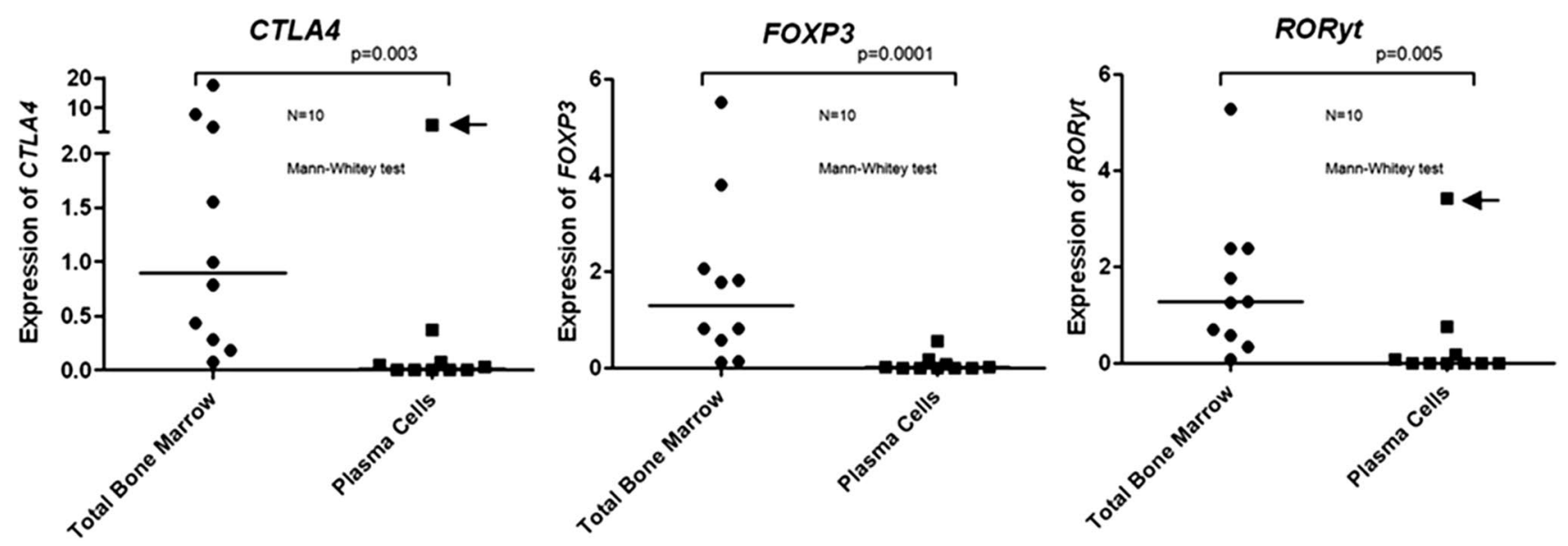

Fig. 1 Relative expression $\left(2^{-\Delta \Delta \mathrm{CT}}\right)$ of FOXP3, CTLA4, and RORyt in sorted plasma cells and their respective total bone marrow aspirates by qPCR. Pilot study with $10 \mathrm{MM}$ cases shows that Treg and
Th17 genes were not significantly expressed by plasma cells, with the exception of one outlier (arrows) for CTLA4 and RORyt 

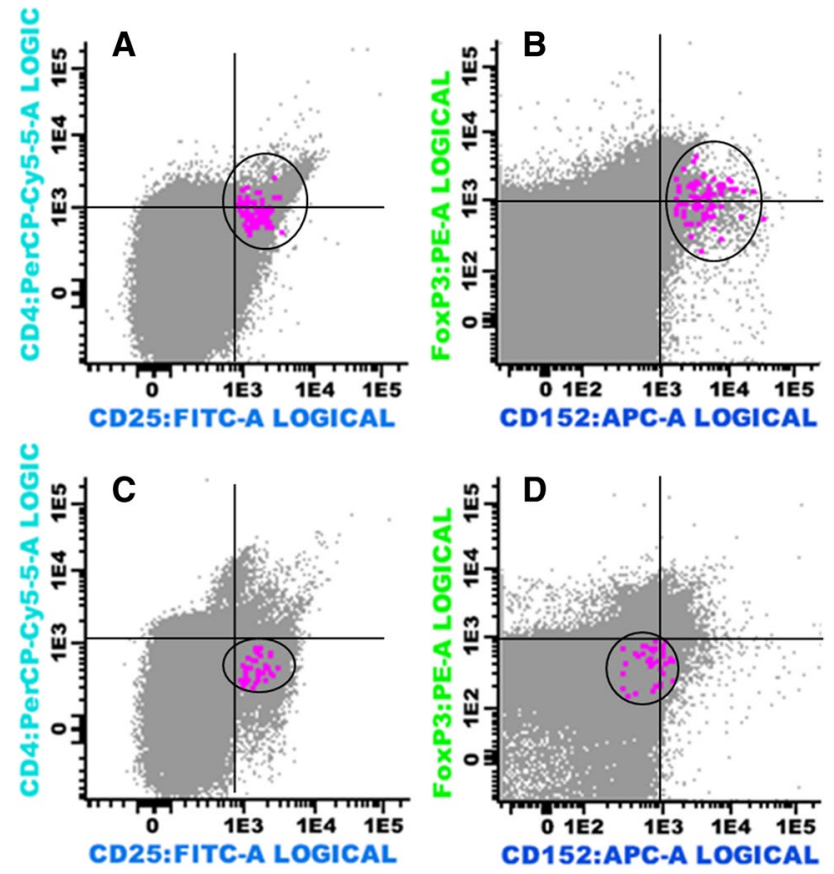

Fig. 2 Multiparameter flow cytometry analysis showing $\mathrm{CD}^{+}$ $\mathrm{CD} 25^{\text {high }}$ immunophenotype in bone marrow aspirate samples from a case of multiple myeloma (a) and a healthy donor (c) (indicated as color dots); FOXP3 ${ }^{+}$CTLA4(CD152) positive (color dots) in the same myeloma sample (b) and negative in the same healthy donor sample (D)

52-fold lower CTLA4 expression $(p=0.003)$, and almost undetectable RORyt expression $(p=0.005)$ when plasma cells samples were compared to total BM (Fig. 1). These data are in agreement with Oncomine cancer profiling database (www.oncomine.org). Therefore, we concluded that the genes analyzed in this study are indeed not expressed by BM-infiltrating myeloma cells, and their expression in whole BM is mainly determined by the local presence of Tregs and Th17 cells.

Next, we analyzed whether real-time PCR would be as useful for quantification of immunomodulating $\mathrm{T}$ cell subsets as flow cytometry (considered the gold standard method in most of the previous studies). Applying both methods to $19 \mathrm{BM}$ samples (13 cases of MM, $1 \mathrm{SP}$, and 2 MGUS patients), as well as 3 healthy donors, we found a linear correlation $(r=0.48 ; p=0.03)$ between the proportion of Tregs $\left(\mathrm{CD} 3{ }^{+} \mathrm{CD} 4{ }^{+} \mathrm{CD} 25^{\text {high }} \mathrm{FOXP} 3{ }^{+} \mathrm{CTLA} 44^{+}\right)$ in total $\mathrm{BM}$ samples as determined by flow cytometry and the expression of CTLA4 assessed by qPCR (Figs. 2, 3a and Supplementary Figure 1).

Having shown that real-time PCR is useful to quantify Tregs and Th17 cells in whole BM samples from myeloma patients, we applied this approach to all samples collected. Treg-related gene FOXP3 was overexpressed in $68 \%$ of individual MM cases, and overall expression was 6.1-fold higher $(p=0.02)$ in MM patients when compared to healthy donors (Fig. 4a). CTLA4 was overexpressed in $76 \%$ of individual $\mathrm{MM}$ cases, and overall expression was 30-fold higher when compared to controls $(p=0.03)$ (Fig. 4b). A strong linear correlation was observed between the expression of genes FOXP3 and CTLA4 (Pearson's' $r=0.83$ and $p<0.0001$ ) (Fig. 3b). In contrast, expression of ROR $t$ was not different when MM patients and healthy controls were compared (Fig. 4c). We also analyzed BM expression of other genes related to Treg and Th17 cell subpopulations. However, BM expression levels of $C D 25, I L 6$, and $T G F \beta 1$ were equivalent in MM patients and healthy controls. IL-17 showed no expression in normal or MM $\mathrm{BM}$ aspirates using two different primer sequences. Median OS of MM patients was 16.8 months (range 4.5-29.1). Univariate analysis indicated that none of the $\mathrm{CD} 4^{+} \mathrm{T}$ cellrelated genes but only ISS $(p=0.011)$ had impact on the patients' prognosis, a finding confirmed by Cox regression analysis ( $p=0.011$, RR 5.04, CI 1.15-22.11) (Table 2).

\section{Discussion}

In this study, we observed the overexpression of FOXP3 and CTLA4 in the BM of myeloma patients when compared to healthy controls. In contrast, Th17-related genes were not differentially expressed in the BM of patients with MM. The virtual absence of FOXP3 and CTLA4 expression in myeloma cells and the linear correlation of CTLA4 gene expression with that of BM-infiltrating Tregs by flow cytometry led us to believe that most of the expression of Treg-related genes in myeloma BM aspirates might be due to the presence of the immunosuppressive $\mathrm{CD}^{+}{ }^{+} \mathrm{T}$ cell subpopulation in tumor microenvironment.

Therefore, our finding of an increased expression of FOXP3 and CTLA4 in BM of MM patients suggests an accumulation of immunosuppressive Tregs in the tumor microenvironment of myeloma patients. We believe that local accumulation of Tregs in the lack of major changes in Th17 gene expression could contribute to the immune imbalance in MM. Of note, accumulating evidence indicates that Th17 cells may provide protection against malignancies by inducing Th1-type chemokines and recruiting effector cells to the tumor site [21]. Tregs, on the other hand, are believed to maintain immunologic tolerance to tumor cells by suppressing the activation and expansion of self-reactive immune cells [22, 23].

We thought to use total BM as the source of samples for this study since our institution has RNA bank available and the study of the T cell compartment inside tumor $\mathrm{BM}$ environment, without manipulation of CD4 subpopulations by sorting looked appealing. A pilot study using ten sorted plasma cells samples (and their respective total 

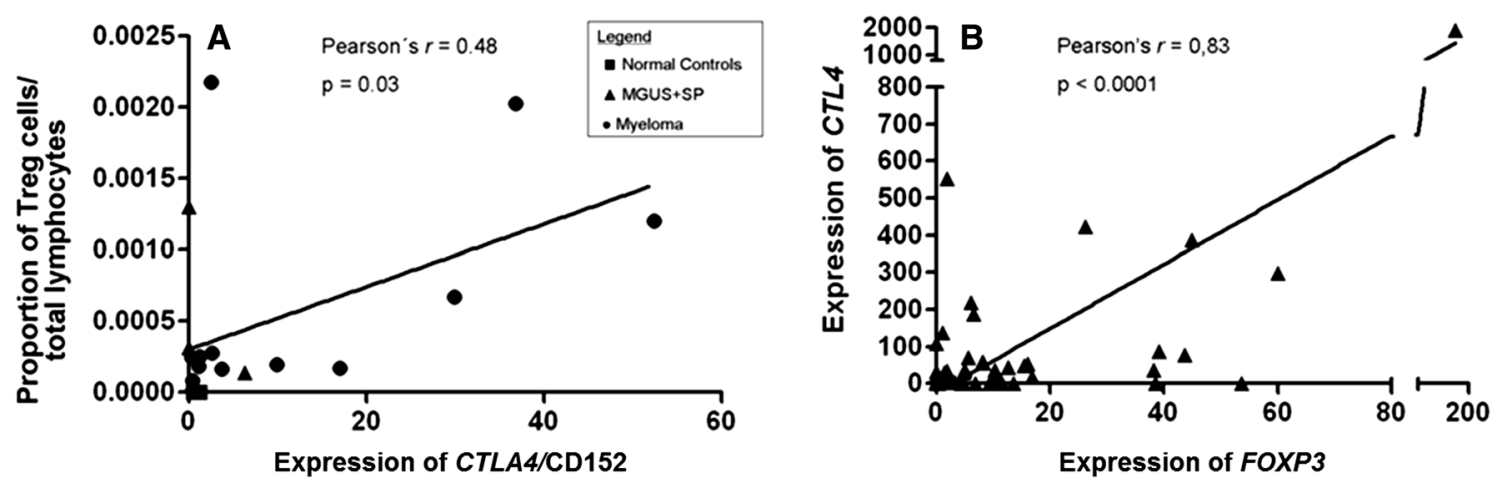

Fig. 3 a Linear correlation between the proportion of Treg cells/total lymphocytes in BM samples by flow cytometry and CTLA4 (CD 152) expression by qPCR in 19 samples: 13 cases of MM, 1 SP, 2 MGUS

patients, and 3 normal controls. b Linear correlation between expression of FOXP3 and CTLA4 in 46 bone marrow aspirates of multiple myeloma (MM) by qPCR
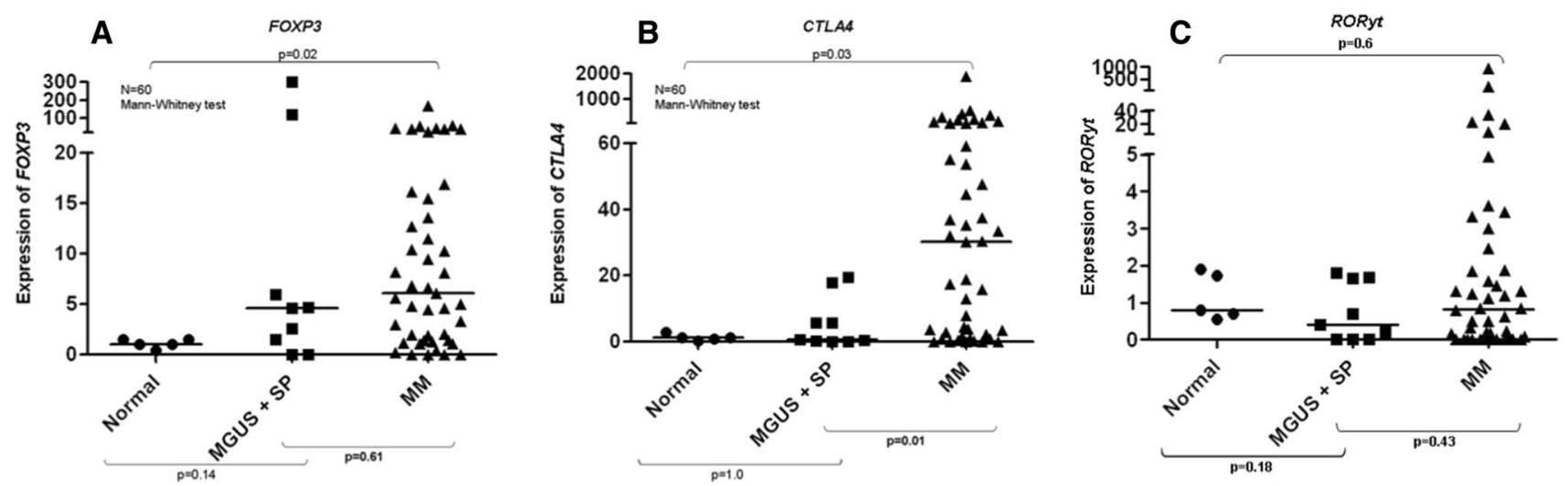

Fig. 4 a Relative expression $\left(2^{-\Delta \Delta C T}\right)$ of FOXP3 in bone marrow aspirates of multiple myeloma (MM), solitary plasmacytomas (SP), monoclonal gammopathy of undetermined significance (MGUS) patients and normal controls by qPCR. b Relative expression $\left(2^{-\Delta \Delta C T}\right)$ of CTLA4 in bone marrow aspirates of multiple myeloma (MM), solitary plasmacytomas (SP), monoclonal gammopathy of undetermined significance (MGUS) patients and normal controls by qPCR. $\mathbf{c}$ Relative expression $\left(2^{-\Delta \Delta \mathrm{CT}}\right)$ of RORyt in bone marrow aspirates of multiple myeloma (MM), solitary plasmacytoma (SP), monoclonal gammopathy of undetermined significance (MGUS) patients and normal controls by $\mathrm{qPCR}$

proportion of Treg cells/total lymphocytes in BM samples by flow cytometry and CTLA4 expression by qPCR in 19 samples, it is also clear that for three of the 16 samples (one MM and 2 MGUS/PS) qPCR and flow cytometry data do not correlate. One possible explanation lies on gene expression regulation both at the transcriptional level and at the posttranscriptional level by posttranslational modifications.

There are a number of studies that have used FOXP3 qPCR as a surrogate for Tregs, with or without previous CD4-positive population sorting [25-27] or RORyt as a surrogate marker of Th17 population [13]. Liu et al. [25] used a similar approach to compare qPCR and flow cytometry adopted in Fig. 3a, to correlate the percentage of demethylation of FOXP3 by real-time PCR and the one of $\mathrm{CD} 4^{+} \mathrm{CD} 25^{\text {hi }} \mathrm{T}$ cells by flow cytometry in cord blood mononuclear cells. 
Table 2 Univariate analysis: overall survival according to ISS, FOXP3, CTLA4, and RORyt expression

\begin{tabular}{lccc}
\hline Factor & $N(\%)$ & Median OS (months) & $p$ value \\
\hline ISS & & & 0.011 \\
1 & $06(13)$ & 36.3 & \\
2 & $13(28)$ & 42.3 & \\
3 & $23(50)$ & 5.4 & 0.690 \\
FOXP3 & & & \\
Underexpressed & $07(15)$ & 3.0 & \\
Normal expression & $08(17)$ & 29.0 & 0.817 \\
Overexpressed & $31(67)$ & 16.8 & \\
CTLA4 & & & \\
Underexpressed & $06(13)$ & 36.3 & 0.447 \\
Normal expression & $05(11)$ & 19.9 & \\
Overexpressed & $35(76)$ & 11.6 & \\
RORyt & & & \\
Underexpressed & $21(46)$ & 16.8 & \\
Normal expression & $13(28)$ & 29 & \\
Overexpressed & $12(26)$ & 2.5 & \\
\hline
\end{tabular}

$N A$ not available

It is important to consider that the obtaining of an "ideal" bone marrow healthy donor is a challenge in this type of study, where the median age of MM patients was 66 years old, ranging from 27 to 95 years. Therefore, in the absence of a better alternative, we used healthy controls that were not age matched, recruited after informed consent among bone marrow donors for allogeneic transplant. We can see in Fig. $4 \mathrm{~b}$ that there is a significant difference in CTLA4 expression between MGUS/PS and MM independent of the age of controls.

The majority of patients in our study was diagnosed with advanced disease (stage III of Durie \& Salmon: $94 \%$ and ISS 2/3: $78 \%$ ) and, despite a significant increase in the expression of genes related to Treg cells, this had no impact on MM OS. Unfortunately, advanced stage MM is part of the reality of all public hospitals in Brazil. In a multicenter study, Hungria et al. [28] found $76.5 \%$ of Durie and Salmon stage III MM cases and $79.9 \%$ ISS 2/3 among 1066 analyzed patients.

In the survival analysis illustrated in Table 2, the markers are scored in three categories, using the same cutoffs defined for gene expression analyses (twofold increment or decrease in comparison with normal samples). Unfortunately, the small number of samples analyzed, and the treatment heterogeneity (only five patients were eligible for autologous stem cell transplantation) also could reduce the chances of achieving a correlation between the expression of the studied genes and clinical outcome.

However, recent studies addressed this topic using different methods and could demonstrate that the percentage of Treg cells isolated from peripheral blood and or bone marrow could have impact in MM outcome. In Giannopoulos et al. [23] study, patients were divided into two cohorts according to median Treg frequency. Those with a high percentage of Treg lived significantly less (median overall survival [OS] of 21 months) as compared with those with lower Treg frequency (median OS not reached at median follow-up of 32 months). The difference in survival was also observed when only non-transplanted patients were analyzed. On the other hand, patients submitted to autologous transplant presented no difference in OS when both groups of Treg frequencies were compared [29]. Raja et al. [30] evaluated Treg cells in both peripheral blood and bone marrow in a larger number of cases of MM using flow cytometry. They found a significantly elevated frequency of Treg cells in a newly diagnosed and relapsed MM patients compared with healthy controls. Functional studies showed that Treg cells from both $\mathrm{MM}$ and controls were similar in their inhibitory function. Using cutoffs very close to Giannopoulos et al. group [23], they showed that MM patients with high percentage of Treg cells had inferior time to progression and this variable had independent prognostic impact by multivariate analysis [30]. Unfortunately, our study could not confirm the above results using two Treg-related gene expressions.

In this study, we also analyzed BM expression of other genes related to Treg and Th17 cell subpopulations. However, BM expression levels of CD25 and TGF $\beta 1$ (Tregrelated genes) were equivalent in MM patients and healthy controls, and IL-17 (Th17-related gene) showed no expression in normal or MM bone marrow aspirates using two different primer sequences. The results were positive only after PCR product reamplification by qPCR. To avoid discrepancies with the expression of other genes, we decided to use only RORyt as a surrogate (and more reliable) marker for Th17. However, it failed to detect any abnormality when normal samples were compared to MM BM aspirates.

An imbalance between Treg and Th17 cells comparable to the one we have observed in the BM of our MM patients has been previously demonstrated in the tumor microenvironment of other malignancies. For example, one study in gastric cancer showed an increased number of Th17 cells as well as Treg in the tumor microenvironment in early stages of the disease. With progression of the cancer, tumor infiltration by Th17 cells gradually decreased while numbers of Tregs increased [31]. It is important to emphasize that Treg and Th17 developmental programs are reciprocally interconnected: upon $\mathrm{T}$ cell receptor (TCR) stimulation, naive $\mathrm{T}$ cells can be driven to express FOXP3 and become Tregs, if TGF $\beta$ is present. However, in the presence of TGF $\beta$ plus IL- 6 or IL-21, the developmental pathway of Tregs is abrogated, and instead, T cells develop into Th17 cells. Only the combination of TGF $\beta$ plus IL- 6 and IL-21, but neither one of them alone, induces a robust production of IL-17 by naive T cells $[32,33]$. Therefore, IL- 6 plays a 
pivotal role in dictating the balance between the generation of Tregs and Th17 cells as indicated by the FOXP3/ROR $\gamma t$ ratio $[5,34]$. Based on the well-known fact that in myeloma, IL-6 is produced in an autocrine and paracrine fashion and promotes the survival and progression of tumor cells; we had expected that the induction of Th17 would have been favored in this malignancy [35]. However, it seems that in MM other factors are involved instead to promote the local accumulation of Tregs and not the development of Th17 cells.

In the opposite direction of our findings, there is also an interesting study in a humanized murine model, showing that ex vivo-cultured human Tregs do not suppress antitumor immunity in BM, but only if the tumor is located outside the BM [34]. Again, using the Treg/Th17 reciprocally interconnected theory, the authors demonstrated that BM stromal cells reverse the suppressive activity of Tregs and promote IL-17 expression in these cells via IL-1 $\beta$ and IL-6 production. Therefore, the authors feel skeptical about the benefits of future Treg-based therapies [36]. Also, BM stromal cell may have an important role in maintaining Treg/Th17 interconnection in MM.

In conclusion, our current study suggests an accumulation of immunosuppressive Tregs in tumor microenvironment of myeloma patients by an overexpression of FOXP3 and CTLA4. Even in a still controversial scenario, we believe that this finding could bring new insights about possible biomarkers and therapeutic targets for MM. Monoclonal antibodies targeting CTLA4, such as ipilimumab, should be evaluated in myeloma as they have been, for example, in melanoma [5]. Alternatively, the depletion of Treg cells, with a possible "reprogramming" of these cells to pro-inflammatory cells, could be a strategy of immunotherapy against human malignancies such as MM [37].

Acknowledgments W.M.T. Braga and G.W.B. Colleoni were partly supported by Conselho Nacional de Desenvolvimento Científico e Tecnológico (CNPq) scholarships. This work was supported by Fundação de Amparo à Pesquisa do Estado de São Paulo (FAPESP) (2010/17668-6), Brazil. We would like to thank Dr. Adriana Seber from Grupo de Apoio ao Adolescente e à Criança com Câncer (GRAAC) for the collection of normal bone marrow samples.

Conflict of interest The authors declare that they have no conflict of interest.

Open Access This article is distributed under the terms of the Creative Commons Attribution License which permits any use, distribution, and reproduction in any medium, provided the original author(s) and the source are credited.

\section{References}

1. Pratt G, Goodyear O, Moss P (2007) Immunodeficiency and immunotherapy in multiple myeloma. Br J Haematol 138:563579. doi:10.1111/j.1365-2141.2007.06705.x
2. Prabhala RH, Neri P, Bae JE, Tassone J, Shammas MA, Allam CK, Daley JF, Chauhan D, Blanchard E, Thatte HS, Anderson KC, Munshi NC (2006) Dysfunctional T regulatory cells in multiple myeloma. Blood 107:301-304. doi:10.1182/ blood-2005-08-3101

3. O'Garra A, Vieira P (2004) Regulatory T cells and mechanisms of immune system control. Nat Med 10:801-805. doi:10.1038/ nm0804-801

4. Adeegbe DO, Nishikawa H (2013) Natural and induced T regulatory cells in cancer. Front Immunol 4:190. doi:10.3389/fi mmu.2013.00190

5. Yuan J, Gnjatic S, Li H, Powel S, Gallardo HF, Ritter E, Ku GY, Jungbluth AA, Segal NH, Rasalan TS, Manukian G, Xu Y, Roman RA, Terzulli SL, Heywood M, Pogoriler E, Ritter G, Old LJ, Allison JP, Wolchok J (2008) CTLA-4 blockade enhances polyfunctional NY-ESO-1 specific T cell responses in metastatic melanoma patients with clinical benefit. Proc Natl Acad Sci USA 105:20410-20415. doi:10.1073/pnas.0810114105

6. Gupta R, Ganeshan P, Hakim M, Verma R, Sharma A (2011) Significantly reduced regulatory $\mathrm{T}$ cell population in patients with untreated multiple myeloma. Leuk Res 35:874-878. doi:10.1016/j.leukres.2010.11.010

7. Beyer M, Kochanek M, Giese T, Endl E, Weihrauch MR, Knolle PA, Classen S, Schultze JL (2006) In vivo peripheral expansion of naive CD4+ CD25high FoxP3 + regulatory T cells in patients with multiple myeloma. Blood 107:3940-3949. doi:10.1182/ blood-2005-09-3671

8. Feyler S, Von Lilienfeld-Toal M, Jarmin S, Marles L, Rawstron A, Ashcroft AJ, Owen RG, Selby PJ, Cook G (2009) $\mathrm{CD} 4{ }^{+} \mathrm{CD} 25^{+} \mathrm{FoxP}^{+}$regulatory $\mathrm{T}$ cells are increased whilst $\mathrm{CD}^{+}{ }^{+} \mathrm{CD} 4^{-} \mathrm{CD}^{-} \alpha \beta \mathrm{TCR}^{+}$double negative $\mathrm{T}$ cells are decreased in the peripheral blood of patients with multiple myeloma which correlates with disease burden. Br J Haematol 144:686-695. doi:10.1111/j.1365-2141.2008.07530.x

9. Yang XO, Nurieva R, Martinez GJ, Kang HS, Chung Y, Pappu BP, Shah B, Chang SH, Schluns KS, Watowich SS, Feng XH, Jetten AM, Dong C (2008) Molecular antagonism and plasticity of regulatory and inflammatory $\mathrm{T}$ cell programs. Immunity 29:44-56. doi:10.1016/j.immuni.2008.05.007

10. Prabhala RH, Pelluru D, Fulciniti M, Prabhala HK, Nanjappa P, Song W, Pai C, Amin S, Tai YT, Richardson PG, Ghobrial IM, Treon SP, Daley JF, Anderson KC, Kutok JL, Munshi NC (2010) Elevated IL-17 produced by TH17 cells promotes myeloma cell growth and inhibits immune function in multiple myeloma. Blood 115:5385-5392. doi:10.1182/blood-2009-10-246660

11. Yang XO, Pappu B, Nurieva R, Akimzhanov A, Kang SH, Chung Y, Ma L, Shah B, Panopoulos AD, Schluns K, Watowich SS, Tian Q, Jetten AM, Dong C (2008) TH17 lineage differentiation is programmed by orphan nuclear receptors $\operatorname{ROR} \alpha$ and $\mathrm{ROR} \gamma$. Immunity 28:29-39. doi:10.1016/j.immuni.2007.11.016.11

12. Li L, Patsoukis N, Petkova V, Boussiotis VA (2012) Runx1 and runx3 are involved in the generation and function of highly suppressive IL-17-producing $\mathrm{T}$ regulatory cells. PLoS ONE 7:e45115. doi:10.1371/journal.pone.0045115

13. Dhodapkar KM, Barbuto S, Matthews P, Kukreja A, Mazumder A, Vesole D, Jagannath S, Dhodapkar MV (2008) Dendritic cells mediate the induction of polyfunctional human IL17producing cells (Th17-1 cells) enriched in the bone marrow of patients with myeloma. Blood 112:2878-2885. doi:10.1182/ blood-2008-03-143222

14. International Myeloma Working Group (2003) Criteria for the classification of monoclonal gammopathies, multiple myeloma and related disorders: a report of the International Myeloma Working Group. Br J Haematol 121:749-757

15. Greipp PR, San Miguel J, Durie BG, Crowley JJ, Barlogie B, Bladé J, Boccadoro M, Child JA, Avet-Loiseau H, Kyle RA, 
Lahuerta JJ, Ludwig H, Morgan G, Powles R, Shimizu K, Shustik C, Sonneveld P, Tosi P, Turesson I, Westin J (2005) International staging system for multiple myeloma. J Clin Oncol 23:34123420. doi:10.1200/JCO.2005.04.242

16. Felix RS, Colleoni GW, Caballero OL, Yamamoto M, Almeida MS, Andrade VC, de Chauffaille ML, Silva WA Jr, Begnami MD, Soares FA, Simpson AJ, Zago MA, Vettore AL (2009) SAGE analysis highlights the importance of $\mathrm{p} 53 \mathrm{csv}$, ddx 5 , mapkapk2 and ranbp2 to multiple myeloma tumorigenesis. Cancer Lett 278:41-48. doi:10.1016/j.canlet.2008.12.022

17. Ayukawa H, Matsubara T, Kaneko M, Hasegawa M, Ichiyama T, Furukawa S (2004) Expression of CTLA-4 (CD152) in peripheral blood $\mathrm{T}$ cells of children with influenza virus infection including encephalopathy in comparison with respiratory syncytial virus infection. Clin Exp Immunol 137(1):151-155. doi:10.1111/j.1365-2249.2004.02502.x

18. Moon HW, Kim BH, Park CM, Hur M, Yun YM, Kim SY, Lee $\mathrm{MH}(2011) \mathrm{CD}^{+} \mathrm{CD}^{2} 5^{\text {high }} \mathrm{FoxP}^{+}$regulatory T-cells in hematologic diseases. Korean J Lab Med 31:231-237. doi:10.3346/j kms.2012.27.9.1009

19. Andrade VC, Vettore AL, Felix RS, Almeida MS, Carvalho F, Oliveira JS, Chauffaille ML, Andriolo A, Caballero OL, Zago MA, Colleoni GW (2008) Prognostic impact of cancer/testis antigen expression in advanced stage multiple myeloma patients. Cancer Immun 8:2

20. Livak KJ, Schmittgen TD (2001) Analysis of relative gene expression data using real-time quantitative PCR and the 2(-Delta Delta C(T)) method. Methods 25:402-408. doi:10.1006/m eth. 2001.1262

21. Kryczek I, Banerjee M, Cheng P, Vatan L, Szeliga W, Wei S, Huang E, Finlayson E, Simeone D, Welling TH, Chang A, Coukos G, Liu R, Zou W (2009) Phenotype, distribution, generation, and functional and clinical relevance of Th17 cells in the human tumor environments. Blood 114:1141-1149. doi:10.1182/ blood-2009-03-208249

22. Beyer M, Schultze JL (2006) Regulatory T cells in cancer. Blood 108:804-811. doi:10.1182/blood-2006-02-002774

23. Pessoa de Magalhães RJ, Vidriales MB, Paiva B, FernandezGimenez C, García-Sanz R, Mateos MV, Gutierrez NC, Lecrevisse Q, Blanco JF, Hernández J, de las Heras N, Martinez-Lopez J, Roig M, Costa ES, Ocio EM, Perez-Andres M, Maiolino A, Nucci M, De La Rubia J, Lahuerta JJ, San-Miguel JF, Orfao A, Spanish Myeloma Group (GEM), Grupo Castellano-Leones de Gammapatias Monoclonales, cooperative study groups (2013) Analysis of the immune system of multiple myeloma patients achieving long-term disease control by multidimensional flow cytometry. Haematologica 98:79-86. doi:10.3324/haema tol.2012.067272

24. Allan SE, Crome SQ, Crellin NK, Passerini L, Steiner TS, Bacchetta R, Roncarolo MG, Levings MK (2007) Activation-induced FOXP3 in human $\mathrm{T}$ effector cells does not suppress proliferation or cytokine production. Int Immunol 19:345-354. doi:10.1093/int $\mathrm{imm} / \mathrm{dxm} 014$

25. Liu J, Lluis A, Illi S, Layland L, Olek S, von Mutius E, Schaub B (2010) T regulatory cells in cord blood-FOXP3 demethylation as reliable quantitative marker. PLoS ONE 5:e13267. doi:10.1371/journal.pone.0013267

26. Saini C, Ramesh V, Nath I (2014) Increase in TGF- $\beta$ secreting $\mathrm{CD} 4{ }^{+} \mathrm{CD} 25^{+} \mathrm{FOXP}^{+} \mathrm{T}$ regulatory cells in anergic lepromatous leprosy patients. PLoS Negl Trop Dis 8:e2639. doi:10.1371/ journal.pntd.0002639

27. Rezvani K, Mielke S, Ahmadzadeh M, Kilical Y, Savani BN, Zeilah J, Keyvanfar K, Montero A, Hensel N, Kurlander R, John Barrett A (2006) High donor FOXP3-positive regulatory T-cell $\left(\mathrm{T}_{\mathrm{reg}}\right)$ content is associated with a low risk of GVHD following HLA-matched allogeneic SCT. Blood 108:1291-1297. doi:10.1182/blood-2006-02-003996

28. HungriaVT, Maiolino A, Martinez G, Colleoni GW, Coelho EO, Rocha L, Nunes R, Bittencourt R, Oliveira LC, Faria RM, Pasquini R, Magalhães SM, Souza CA, Pinto Neto JV, Barreto L, Andrade E, Portella MS, Bolejack V, Durie BG, International Myeloma Working Group Latin America (2008) Confirmation of the utility of the international staging system and identification of a unique pattern of disease in Brazilian patients with multiple myeloma. Haematologica 93(5):791-792. doi:10.3324/haematol.11637

29. Giannopoulos K, Kaminska W, Hus I, Dmoszynska A (2012) The frequency of $\mathrm{T}$ regulatory cells modulates the survival of multiple myeloma patients: detailed characterisation of immune status in multiple myeloma. Br J Cancer 106:546-552. doi:10.1038/ bjc. 2011.575

30. Raja KRM, Rihova L, Zahradova L, Klincova M, Penka M, Hajek $R$ (2012) Increased $T$ regulatory cells are associated with adverse clinical features and predict progression in multiple myeloma. PLoS ONE 7(10):e47077. doi:10.1371/journal.pone.004707

31. Maruyama T, Kono K, Mizukami Y, Kawaguchi Y, Mimura K, Watanabe M, Izawa S, Fujii H (2010) Distribution of Th17 cells and FoxP3(+) regulatory $\mathrm{T}$ cells in tumor-infiltrating lymphocytes, tumor-draining lymph nodes and peripheral blood lymphocytes in patients with gastric cancer. Cancer Sci 101:1947-1954. doi:10.1111/j.1349-7006.2010.01624.x

32. Chen W, Jin W, Hardegen N, Lei KJ, Li L, Marinos N, McGrady G, Wahl SM (2003) Conversion of peripheral CD4+ CD25naïve $\mathrm{T}$ cells to $\mathrm{CD} 4+\mathrm{CD} 25+$ regulatory $\mathrm{T}$ cells by TGF- $\beta$ induction of transcription factor Foxp3. J Exp Med 198:18758186. doi:10.1084/jem.20030152

33. Kretschmer K, Apostolou I, Hawiger D, Khazaie K, Nussenzweig MC, von Boehmer H (2005) Inducing and expanding regulatory $\mathrm{T}$ cell populations by foreign antigen. Nat Immunol 6:12191227. doi:10.1038/ni1265

34. Zhou L, Lopes JE, Chong MM, Ivanov II, Min R, Victora GD, Shen Y, Du J, Rubtsov YP, Rudensky AY, Ziegler SF, Littman DR (2008) TGF- $\beta$-induced Foxp3 inhibits TH17 cell differentiation by antagonizing ROR $\gamma$ t function. Nature 453:236-240. doi:10.1038/nature06878

35. Korn T, Bettelli E, Oukka M, Kuchroo VK (2009) IL-17 and Th17 Cells. Annu Rev Immunol 27:485-517. doi:10.1146/annur ev.immunol.021908.132710

36. Guichelaar T, Emmelot ME, Rozemuller H, Martini B, Groen RW, Storm G, Lokhorst HM, Martens AC, Mutis T (2013) Human regulatory $\mathrm{T}$ cells do not suppress the antitumor immunity in the bone marrow: a role for bone marrow stromal cells in neutralizing regulatory T cells. Clin Cancer Res 19:1467-1475. doi:10.1158/1078-0432.CCR-12-2177

37. Sharma MD, Hou DY, Liu Y, Koni PA, Metz R, Chandler P, Mellor AL, He Y, Munn DH (2009) Indoleamine 2,3-dioxygenase controls conversion of Foxp3 Tregs to TH17-like cells in tumordraining lymph nodes. Blood 113:6102-6111. doi:10.1182/ blood-2008-12-195354 